\title{
PROMOTING OLD-AGE VITALITY IN THE PEOPLE'S REPUBLIC OF CHINA
}

YiZeng

NO. 25

December 2019
ADB EAST ASIA WORKING PAPER SERIES 
ADB East Asia Working Paper Series

\section{Promoting Old-Age Vitality in the People's Republic of China}

\section{Yi Zeng}

No. 25 | December 2019
Yi Zeng is a professor at the National School of Development; chief scientist at the Raissun Institute for Advanced Studies, Peking University; and professor at the Center for Study of Aging and Human Development and Geriatrics Division, School of Medicine, Duke University. 
(C) 2019 Asian Development Bank

6 ADB Avenue, Mandaluyong City, 1550 Metro Manila, Philippines

Tel +632 8632 4444; Fax +63286362444

www.adb.org

Some rights reserved. Published in 2019.

Printed in the Philippines

Publication Stock No. WPS190616-2

DOI: http://dx.doi.org/10.22617/WPS190616-2

The views expressed in this publication are those of the authors and do not necessarily reflect the views and policies of the Asian Development Bank (ADB) or its Board of Governors or the governments they represent.

ADB does not guarantee the accuracy of the data included in this publication and accepts no responsibility for any consequence of their use. The mention of specific companies or products of manufacturers does not imply that they are endorsed or recommended by ADB in preference to others of a similar nature that are not mentioned.

By making any designation of or reference to a particular territory or geographic area, or by using the term "country" in this document, $A D B$ does not intend to make any judgments as to the legal or other status of any territory or area.

This work is available under the Creative Commons Attribution 3.0 IGO license (CC BY 3.0 IGO)

https://creativecommons.org/licenses/by/3.0/igo/. By using the content of this publication, you agree to be bound by the terms of this license. For attribution, translations, adaptations, and permissions, please read the provisions and terms of use at https://www.adb.org/terms-use\#openaccess.

This CC license does not apply to non-ADB copyright materials in this publication. If the material is attributed to another source, please contact the copyright owner or publisher of that source for permission to reproduce it. $A D B$ cannot be held liable for any claims that arise as a result of your use of the material.

Please contact pubsmarketing@adb.org if you have questions or comments with respect to content, or if you wish to obtain copyright permission for your intended use that does not fall within these terms, or for permission to use the ADB logo.

Corrigenda to ADB publications may be found at http://www.adb.org/publications/corrigenda.

Notes:

In this publication, “\$” refers to United States dollars.

ADB recognizes "China” as the People's Republic of China.

The ADB East Asia Working Paper Series is a forum for stimulating discussion and eliciting feedback on ongoing and recently completed research and policy studies undertaken by the East Asia Department of the Asian Development Bank (ADB) staff, consultants, or resource persons. The series deals with key economic and development problems, as well as conceptual, analytical, or methodological issues relating to project/program economic analysis, and statistical data and measurement. The series aims to enhance the knowledge on Asia's development and policy challenges; strengthen analytical rigor and quality of ADB's country partnership strategies, and its subregional and country operations; and improve the quality and availability of statistical data and development indicators for monitoring development effectiveness.

The ADB East Asia Working Paper Series is a quick-disseminating, informal publication whose titles could subsequently be revised for publication as articles in professional journals or chapters in books. The series is maintained by the East Asia Department.

This paper was prepared as a background study for the preparation of the High-Level Round Table Discussion on the People's Republic of China's transition to high-quality development, coordinated by the Asian Development Bank. 


\section{CONTENTS}

TABLE AND FIGURES iv

ABSTRACT

ABBREVIATIONS vi vi vion

$\begin{array}{ll}\text { I. INTRODUCTION } & 1\end{array}$

II. THE CHINESE LONGITUDINAL HEALTHY LONGEVITY SURVEY 1

A. Mental and Physical Health across Different Elderly Age Groups 2

B. Dynamic Disability Trends among the Oldest-Old 4

C. The Greater Seriousness of Population Aging in Rural Areas 7

D. Effects of Demographic Factors and the Retirement Age on Future Pension Deficits 7

III. POLICY IMPLICATIONS AND RECOMMENDATIONS $\quad 7$

A. Further Develop Healthy Aging Intervention Programs

B. Prioritize Programs to Improve Elderly Mental Health 8

C. Strengthen the Rural Old-Age Insurance Program 8

D. Gradually Raise the Retirement Age 9

$\begin{array}{ll}\text { IV. CONCLUSIONS } & 9\end{array}$

$\begin{array}{ll}\text { REFERENCES } & 10\end{array}$ 


\section{TABLE AND FIGURES}

\section{TABLE}

1 The Age and Sex Structure of the Chinese Longitudinal Healthy Longevity Survey Waves, 1998-2018

\section{FIGURES}

1 Age Patterns of Activities of Daily Living, Good Cognition, Ability to Turn 360 Degrees, Self-Reported Good Health, and Life Satisfaction, 2008-2009

2 Evidence Supporting "Benefits of Success" with Increased Longevity (Death Rates and Activities of Daily Living), 1998 and 2008-2009

3 Evidence Supporting "Costs of Success" with Increased Longevity (Cognitive Function and Physical Performance), 1998 and 2008-2009

4 Comparison of Perceived Well-Being between Earlier and Later Oldest-Old Cohorts, 1998 and 2008-2009 


\begin{abstract}
This paper examines old-age vitality and its associated factors, including physical and mental health, in the People's Republic of China (PRC), using the Chinese Longitudinal Healthy Longevity Survey and census data sets. Population aging is a far more serious problem in rural than in urban areas; and the effects of fertility, mortality, and the retirement age on future pension deficits are substantial. The paper discusses the policy implications of these trends and offers recommendations to promote old-age vitality. It is important to develop public and private programs to provide individualized healthy aging services to meet the various needs of the PRC's growing elderly population. Policies to promote healthy aging should prioritize the strengthening of services and intervention programs to improve the mental health of the elderly. The other strategically important policies would include further developing the rural old-age insurance program and gradually raising the retirement age.
\end{abstract}




\section{ABBREVIATIONS}

ADL activity of daily living

CLHLS Chinese Longitudinal Healthy Longevity Survey

PRC People's Republic of China 


\section{INTRODUCTION}

The average life expectancy at birth in the People's Republic of China (PRC) increased dramatically, from 44.5 years in 1950-1955 to 74.9 years in 2010 (Xiong, Gu, and Zeng 2019). But fertility has dramatically declined, from 6.00 children per woman in the 1950s and 1960s to 1.63 children per woman in 2010. The large cohorts of baby boomers born in the 1950s and 1960s will be entering old age in the next few decades. So, the PRC's population is aging at an extraordinarily rapid speed and on a large scale (Banister et al. 2010; Peng 2011; Zeng and Wang 2014).

This paper examines old-age vitality to provide a more comprehensive framework for assessing the impact of population aging. It uses the Chinese Longitudinal Healthy Longevity Survey (CLHLS) and census data sets to do an empirical analysis of various aspects of old-age vitality, including mental health, the problem of population aging in rural areas, and the effects of demographic factors and the retirement age on future pension deficits. The paper then discusses policy implications and proposes recommendations. These include further developing healthy aging intervention programs, especially those promoting elderly mental health; strengthening the rural old-age insurance program; and gradually raising the age of retirement.

\section{THE CHINESE LONGITUDINAL HEALTHY LONGEVITY SURVEY}

The CLHLS has been collecting extensive data since 1998. It has the world's largest sample of the oldestold (aged 80 and over), who are the most likely to need daily life and medical care, and a compatible sample of younger elders, ages 65-79. The CLHLS is conducted in randomly selected halves of counties and cities in 23 of the PRC's 31 provinces (Zeng 2012). The overwhelming majority of the population in the 23 provinces are Han Chinese, whose age reporting is reasonably good (Coale and Li 1991; Wang et al. 1998; Poston, Jr, and Luo 2004). The total population of the survey areas constitutes about $85 \%$ of the PRC's total population (Zeng, Feng, Gu et al. 2017). Eight waves of data were collected: in 1998, 2000, 2002, 2005, 2008-2009, 2011-2012, 2014, and 2017-2018.

Within the sampled counties and cities, the CLHLS aimed to interview all centenarians who agreed to participate in the survey. For each centenarian interviewee, one nearby nonagenarian (ages 90-99) and one nearby octogenarian (ages 80-89) of a predefined age and sex was selected in the same county or city, or in a neighboring county or city, for voluntary participation in the survey. Using the same sampling strategy, three participants ages 65-79 were surveyed for every two centenarians interviewed, starting with the 2002 wave (Zeng, Feng, Gu et al. 2017). Respondents who died, could not be traced, or refused to be interviewed during a subsequent wave were replaced by new interviewees in the same sex and age group during the 2000, 2002, 2005, 2008-2009, and 2017-2018 waves.

Table 1 shows that over the eight waves from 1998 to 2018, the CLHLS conducted 112,701 interviews, including 19,426 centenarians, 26,773 nonagenarians, 29,736 octogenarians, 25,240 younger elders (aged 65-79), and 11,556 adults (aged 35-64). For the 28,481 participants who died between waves, data on mortality and the degree and length of disability before death were collected in interviews with a close family member of the deceased. The CLHLS collected DNA samples from 38,705 participants of the eight waves, including 7,099 centenarians, 8,221 nonagenarians, 8,927 octogenarians, 9,765 younger elders, and 4,692 adults. 
Table 1: The Age and Sex Structure of the Chinese Longitudinal Healthy Longevity Survey Waves, 1998-2018

\begin{tabular}{|c|c|c|c|c|c|c|}
\hline \multirow[b]{2}{*}{ Age } & \multicolumn{3}{|c|}{ Number of Interviews with Surviving Participants } & \multicolumn{3}{|c|}{$\begin{array}{c}\text { Number of Interviews with a Family Member of } \\
\text { Deceased Participants }\end{array}$} \\
\hline & Men & Women & Total & Men & Women & Total \\
\hline $35-64$ & 7,263 & 4,293 & 11,556 & 4 & 2 & 6 \\
\hline $65-79$ & 13,124 & 12,116 & 25,240 & 966 & 677 & 1,643 \\
\hline $80-89$ & 14,762 & 14,974 & 29,736 & 3,262 & 2,548 & 5,810 \\
\hline $90-99$ & 11,392 & 15,381 & 26,773 & 4,778 & 5,740 & 10,518 \\
\hline $100+$ & 4,089 & 15,337 & 19,426 & 2,304 & 8,200 & 10,504 \\
\hline Total & 50,630 & 62,101 & 112,701 & 11,314 & 17,167 & 28,481 \\
\hline
\end{tabular}

Source: Chinese Longitudinal Healthy Longevity Survey, 1998-2018.

The CLHLS used various sources to verify the ages of the participants, especially the oldest-old individuals, including birth and marriage certificates; household registration booklet information; the ages of their siblings, children, and relatives; genealogical records; relevant documents from local aging committee offices, if available; and reported ages in the form of Chinese zodiac animals. The CLHLS also verified the accuracy of age reporting at the aggregate level. This was done by using indicators such as the single-age distribution of centenarians, the age-progressive ratio of very old adults (e.g., ages 90 and older), and centenarian density among those aged 80 and over (Zeng et al. 2017). These were compared with indices from countries with good-quality data. The comparisons showed that the quality of age reporting of the Han Chinese oldest-old was not as good as in Sweden, Japan, England, and Wales. But it was almost as good as in Australia and Canada, slightly better than the average for the racial groups in the United States, and much better than in Chile (Zeng and Gu 2008).

Another approach used to verify the accuracy of age reporting at the population level was to check whether age- and sex-specific death rates followed a general age-sex trajectory pattern that was commonly found in other populations with good data quality. Gu and Dupre (2008) found that the single-age-sex-specific mortality rates of the oldest-old, including centenarians, fit well with the Kannisto model, a function that has been shown to best reflect the human mortality trajectories for the oldest-old in many countries with high-quality data (Thatcher, Kannisto, and Vaupel 1998). These results support the conclusion that the accuracy of age reporting for the oldest-old and the younger elderly in the CLHLS was reasonably good (Gu and Dupre 2008).

\section{A. Mental and Physical Health across Different Elderly Age Groups}

Using the cross-sectional data from the CLHLS's fifth wave (2008), Figure 1 shows that the proportion of the elderly who were active in daily life and had good physical performance capacity (being able to turn around 360 degrees), as well as good cognitive functioning, dropped dramatically from ages 65-69 to $100+$. Cognitive function is measured by the international Mini-Mental State Examination. By contrast, the percentage of self-reported life satisfaction and self-reported good health remains almost constant or even slightly increases from ages 65-69 to 100+. The interesting pattern shown in Figure 1 has been repeatedly reconfirmed by different waves of the CLHLS (Zeng and Vaupel 2002; Zeng 2012; Zeng et al. 2017). This pattern reveals that long-lived people, especially centenarians (aged 100 and over) and nonagenarians (aged 90-99), tend to maintain stable life satisfaction despite their much-reduced capacities for daily activities, physical performance, and cognitive function. 


\section{Figure 1: Age Patterns of Activities of Daily Living, Good Cognition, Ability to Turn 360 Degrees, Self-Reported Good Health, and Life Satisfaction, 2008-2009 (\%)}

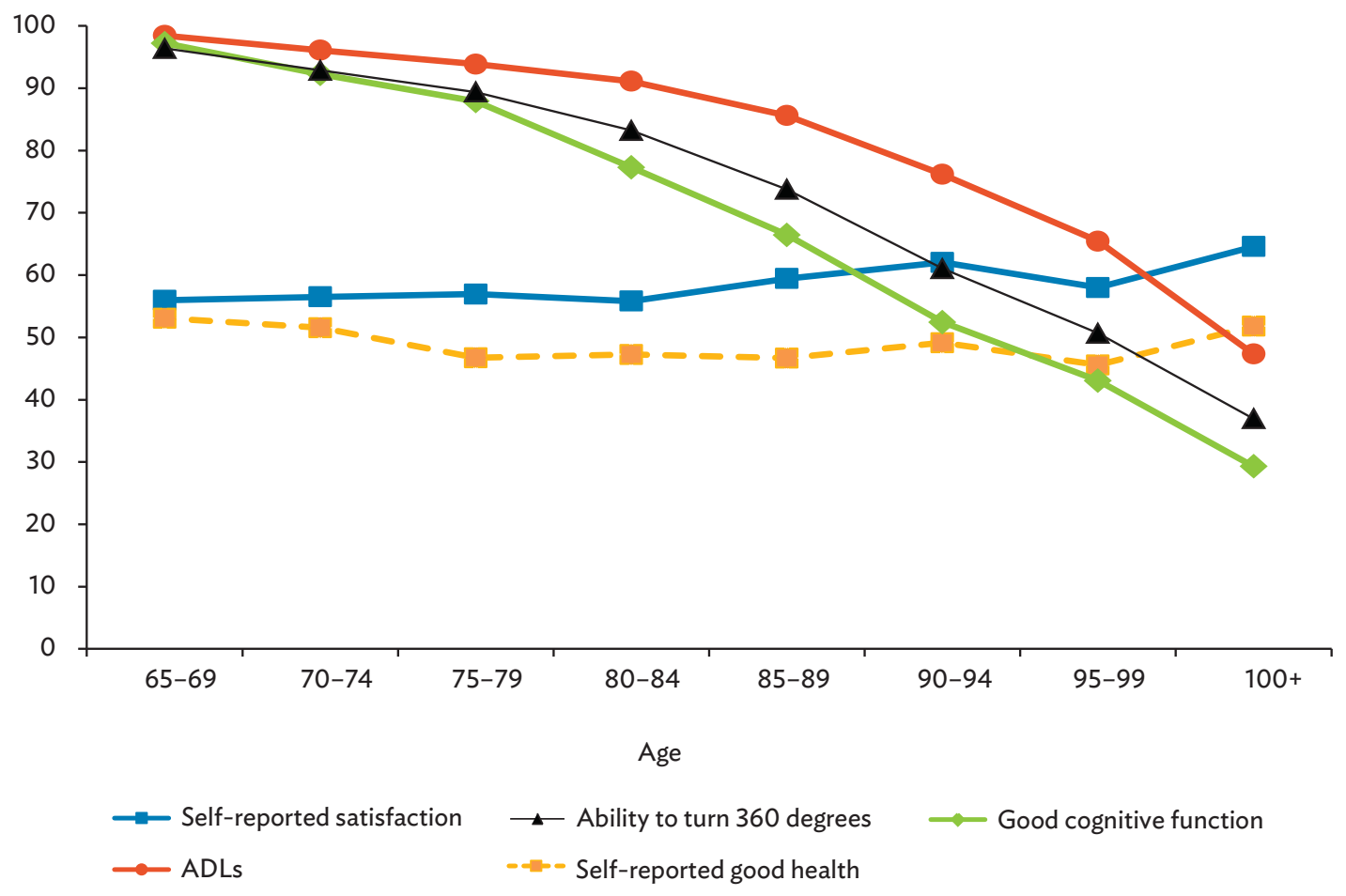

ADLs = activities of daily living.

Note: "Good cognitive function" refers to a score on the Mini-Mental State Examination of at least 25 out of 30.

Source: Chinese Longitudinal Healthy Longevity Survey, 2008-2009.

A longitudinal study in the United States also found that life satisfaction does not decrease with advanced old age (Field and Millsap 1991). Blazer, Fillenbaum, and Burchett (1991), in their study of 3,998 people aged 65 and over in the United States, found that the oldest-old suffered fewer depressive symptoms compared with younger age groups when other variables, such as age, gender, income, physical disability, cognitive impairment, and social support, are controlled for (Zeng et al. 2017). The CLHLS findings, based on an unprecedented large data set of the oldest-old and compatible younger elderly in the largest developing country, are consistent with the previous studies conducted in the United States.

These findings imply that an optimistic outlook is the key determinant of healthy longevity. This is because centenarians and nonagenarians are the most likely to have been optimistic about the future and to view their lives as "satisfactory." Without these attributes, they might not have been able to reach such advanced ages. The old Chinese saying, “Knowing satisfaction leads to constant happiness (知足 常乐)," illustrates the connection between life satisfaction and happiness; and they, in turn, promote healthy longevity (Zeng and Vaupel 2002). 


\section{B. Dynamic Disability Trends among the Oldest-Old}

The oldest-old group is the most rapidly growing demographic in the PRC, as well as globally. This group is also in the most in need of health care and other assistance. An important aging policy question is whether increased longevity leads to increased populations of healthier senior elderly (compression of disability) or increased populations of less healthy and disabled senior elderly (expansion of disability).

To answer this important question, Zeng et al. (2017) analyzed the CLHLS data, focusing on three pairs of cohorts, aged 80-89, 90-99, and 100-105 (in total 19,528 oldest-old participants). The two cohorts in each pair were born 10 years apart, but were at the same age at the time of their assessments, in the 1998 or 2008 CLHLS wave. The authors found that, controlling for various complicating factors, the death rates for oldest-old age among the later cohorts were substantially reduced annually, by $0.2 \%-$ $1.3 \%$, compared with the cohorts born 10 years earlier. Their disabilities with regard to activities of daily living (ADLs) were also significantly reduced annually: by $0.8 \%-2.6 \%$ (Figure 2 ). However, the cognitive impairment rates of the later cohorts increased annually by $0.7 \%-2.2 \%$, which is consistent with the trends found in other studies in the PRC; Hong Kong, China; and Taipei,China (Wu et al. 2014; Chan et al. 2013). Objective physical performance capacity (standing up from a chair, picking up a book from floor, and turning around 360 degrees) decreased annually by $0.4 \%-3.8 \%$ (Figure 3 ).

Figure 2: Evidence Supporting "Benefits of Success" with Increased Longevity (Death Rates and Activities of Daily Living), 1998 and 2008-2009

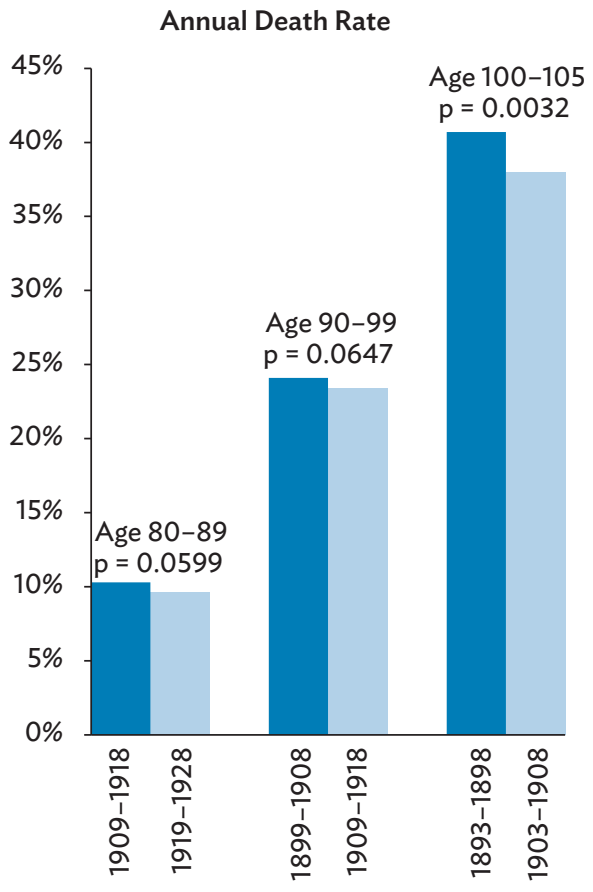

Birth Years of the Cohorts

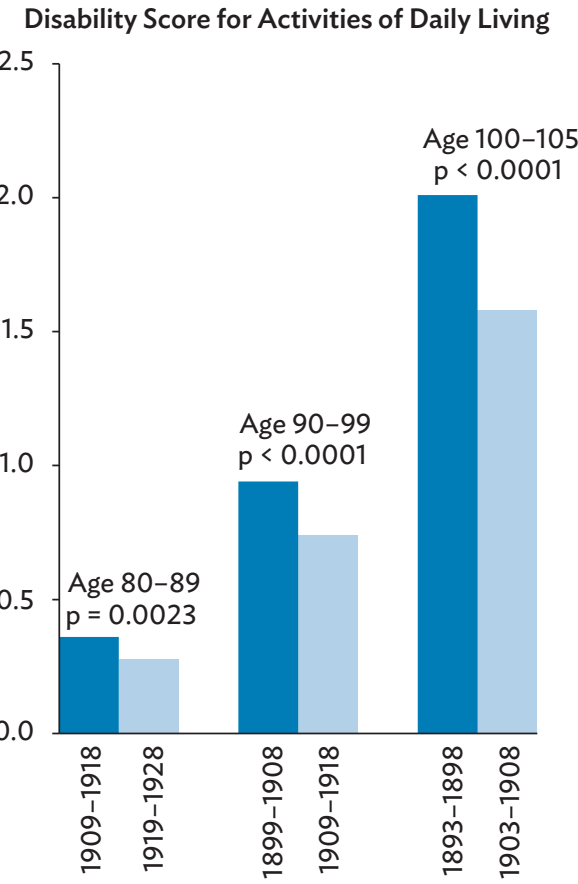

Birth Years of the Cohorts

Note: The results shown in this figure are based on the combined data of both genders.

Source: Chinese Longitudinal Healthy Longevity Survey, 1998 and 2008-2009. 


\section{Figure 3: Evidence Supporting “Costs of Success” with Increased Longevity (Cognitive Function and Physical Performance), 1998 and 2008-2009}

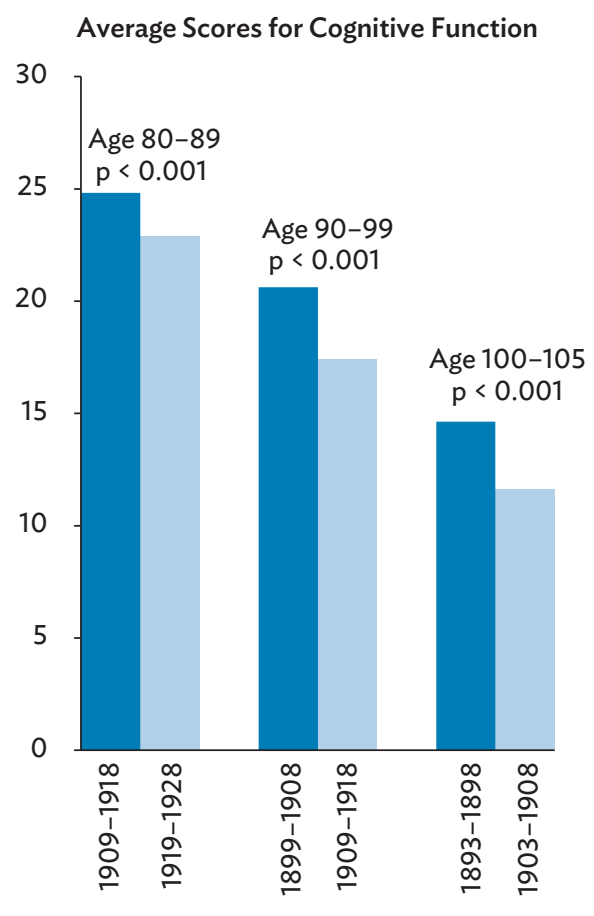

Birth Years of the Cohorts

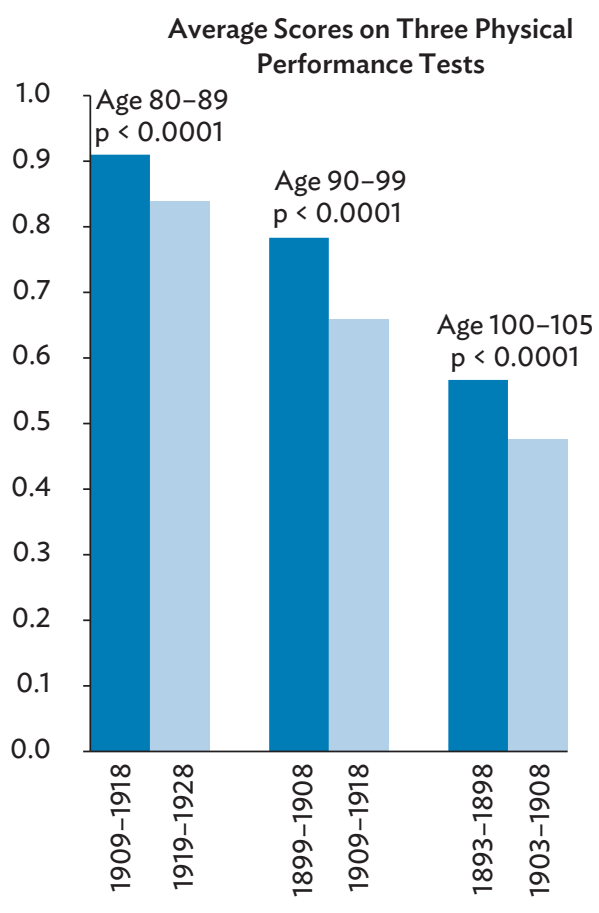

Birth Years of the Cohorts

Notes:

1. The results shown in this figure are based on the combined data for both genders.

2. The three performance tests cover the ability to...

Source: Chinese Longitudinal Healthy Longevity Survey 1998 and 2008-2009.

The findings in Figures 2 and 3 on survival and self-reported ADL abilities seem to contradict the objective measures of physical performance and cognitive function. Two underlying factors may help to explain this discrepancy. The first is the mixed effects of the two opposing processes: the compression of morbidity (benefits of success) and the expansion of morbidity (costs of success). On the one hand, the later cohorts might have benefitted from the progress made in the treatment of certain diseases; healthier lifestyles; the declining disability effects of some major chronic diseases, such as stroke and cardiometabolic disease (Liang et al. 2015); and improved standards of living, due to the rapid socioeconomic development of the PRC. The benefits of success imply that the later oldest-old cohort had reduced mortality rates due to postponed senescence, and that participants in that cohort reached older ages with improved health and functional capacity in daily living (Vaupel 2010). On the other hand, the later cohort may have had more members who survived life-threatening conditions because of improvements in medical care and increased longevity, but who remained in relatively poor health. In other words, saving lives will reduce the death rate, but it might also reduce the average physical and cognitive functional capacity and health of the cohort overall (Christensen et al. 2013). Zeng et al. (2017) call this the "costs of success." 
The second underlying factor is associated with living conditions. Disability as measured by self-reported ADLs depends not only on health status, but also on the available facilities that can assist the ADLs, such as moving around, using the toilet, and bathing. The substantial improvement in ADL capacity in the PRC's oldest-old could be partly due to the rapid changes in living standards and the increased availability of such facilities in the past few decades (Liang et al. 2015). The average annual disposable income of urban and rural households in 2008 was 3.0 times higher (urban) and 2.2 times higher (rural) than in 1998. This rapid improvement in living conditions, which implies better facilities for daily life, could help to explain the significant decrease in disability associated with ADLs. However, the objective tests of physical performance and cognitive function do not depend on the use of such facilities.

The average rates of self-reported life satisfaction and good health substantially declined among the later oldest-old cohorts, compared with the rates for the earlier cohorts when they were the same age (Figure 4). This is understandable: The scores of the later cohorts for physical performance and cognitive function declined significantly as they aged. Given that their higher living standards had raised their expectations for a good life and good health, they may have felt more disappointed.

Figure 4: Comparison of Perceived Well-Being between Earlier and Later Oldest-Old Cohorts, 1998 and 2008-2009 (\%)

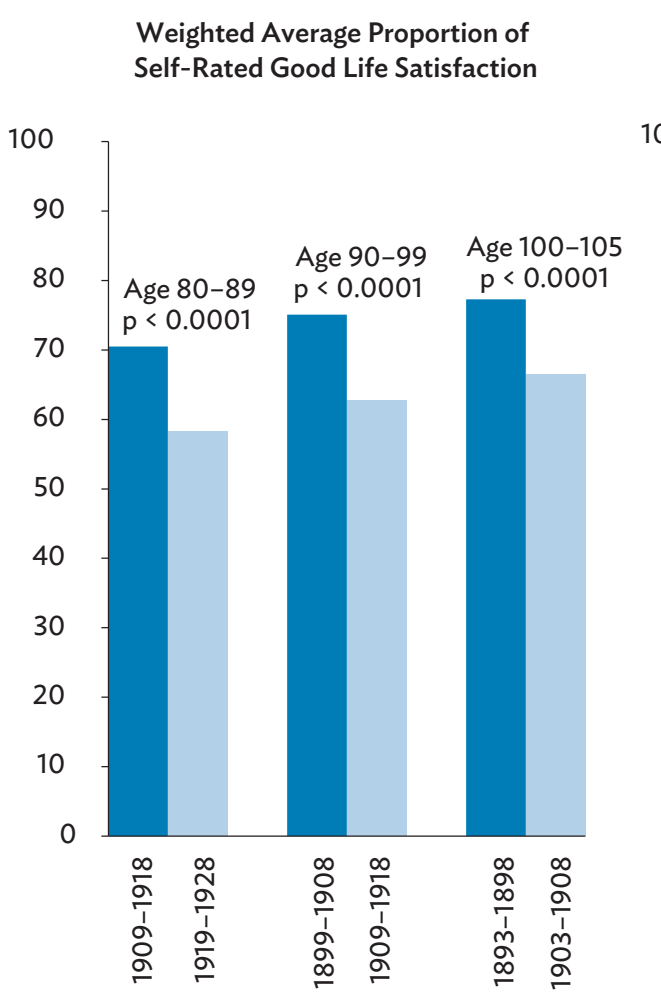

Birth Years of the Cohorts
Weighted Average Proportion of Self-Rated Good Health

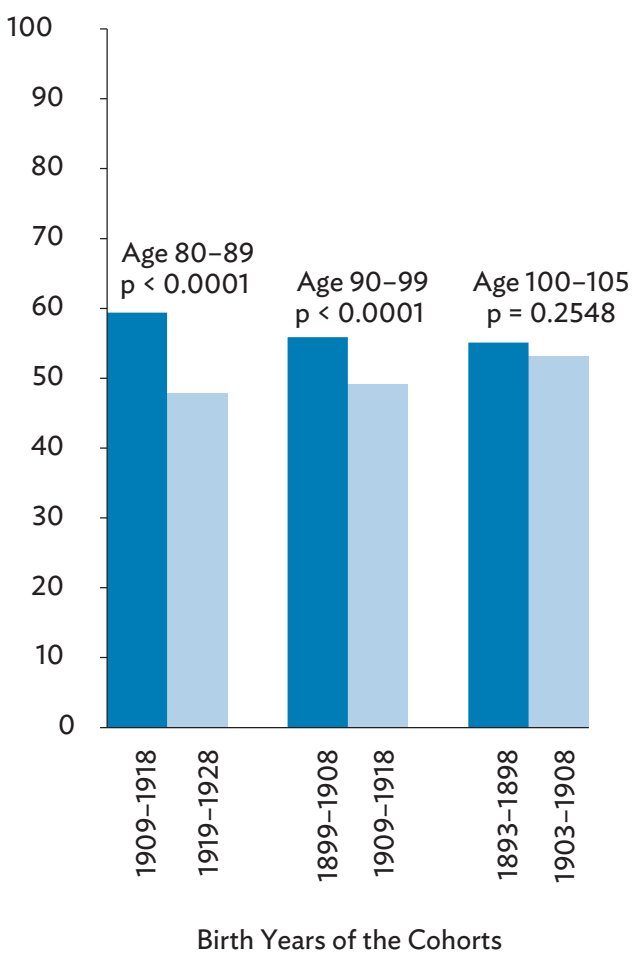

Note: The results shown in this figure are based on two genders' combined data.

Source: Chinese Longitudinal Healthy Longevity Survey, 1998 and 2008-2009. 


\section{The Greater Seriousness of Population Aging in Rural Areas}

In the PRC, population aging is a far more serious problem in rural than in urban areas because of the large numbers of young rural migrants moving to the cities (Banister, Bloom, and Rosenberg 2010). Zeng and Wang (2014) analyzed rural-urban differentials based on population and household aging projections classified by rural and urban areas. The projection results show that the proportion of elderly aged 65 over in the total rural population in 2050 will be about twice as high as that in the urban areas (Zeng and Wang 2014, Table 2), and the proportion of elderly living in empty-nest households in rural areas in 2050 will be well over twice as high as that in the urban areas (Zeng and Wang 2014, Table 3). This holds both for the medium-fertility scenario (with a universal two-child policy) and the low-fertility scenario (with the previous rigorous one-child policy).

These scenarios are based on the assumption that the urban population will increase from $50 \%$ of the PRC's total population in 2010 to 87\% in 2050, and that future rural-urban migration will follow the age pattern of single-age-specific frequency distributions of rural-to-urban migrants, who are mostly young people, as estimated based on the 2010 Population Census micro-data sample. Clearly, the large outflows of rural young people during the rapid urbanization process helped accelerate the aging of the population in rural areas, even though fertility in rural areas is substantially higher than in the cities.

\section{Effects of Demographic Factors and the Retirement Age on Future Pension Deficits}

Zeng (2011) proposes a simple method for projecting the annual pension deficit, based on: the oldage dependency ratio (determined by demographic factors of fertility, mortality, and migration); the retirement age; and a few pension program parameters that can be predicted by extrapolating trends or consulting expert opinion. Applied to the PRC, the results show that if the compulsory retirement age were raised gradually from its current very low level (age 60 for men and 55 for women) to the current international standard ( 65 for both men and women) by 2050 , the annual pension deficit rate would be substantially reduced or even eliminated by mid-century under various demographic scenarios.

With everything else being equal, the annual pension deficit rate after 2030 under the medium-fertility scenario (with a universal two-child policy) would be much lower than that under the low-fertility scenario (with an unchanged one-child policy). This is an additional reason, on top of many others, why the PRC, in late 2015 or even earlier, saw the need to transition toward a two-child policy as soon as possible. In addition, a sensitivity analysis indicated that the impact of a potentially faster decline in the mortality rate would be relatively moderate.

\section{POLICY IMPLICATIONS AND RECOMMENDATIONS}

\section{A. Further Develop Healthy Aging Intervention Programs}

The population of the PRC, as in many other countries, is aging rapidly, with the oldest-old growing much faster than any other age group. The findings described in this paper's section on dynamic disability trends among the oldest-old, and the results of other recent research (e.g., Christensen et al. 2013; Zeng et al. 2017), are a clear warning to the PRC and other countries facing rapid population aging: Although people are living longer and some health indicators are improving (benefits of success), some 
major health indicators may get worse (costs of success), posing enormous challenges to a country's health-care system, social care, and families. These findings are thus a call to action. The PRC must develop effective and individualized healthy aging services and intervention programs in order to tackle the challenges of population aging, while maximizing the benefits of success and reducing the costs of success resulting from longer life spans.

The most effective way to improve the health and vitality of the elderly will not only be to cure diseases, but also to prevent illnesses. The latter is more important, as the elderly who are cured of one illness are more likely to suffer from another illness and long-term disability if there is no improvement in their ability to prevent disease. Further research is also needed on why some elderly achieve happiness and vitality up to the oldest-old ages, and on how intervention programs can assist the elderly in maintaining good health.

\section{B. Prioritize Programs to Improve Elderly Mental Health}

One finding of the empirical analysis of mental and physical health across different elderly age groups is that good mental health, particularly an optimistic outlook, is a key determinant of healthy aging, and should thus be the priority of intervention programs. A considerable body of research confirms that mental health is crucial for physical health, treatment, recovery, and social participation (Kahn, Hessling, and Russell 2003). A saying in science is that there is "no health without mental health" (Prince et al. 2007). On the basis of the empirical research findings presented in this paper and many other studies, the PRC government should implement programs to promote the psychological well-being of the elderly as an essential component of healthy aging.

\section{Strengthen the Rural Old-Age Insurance Program}

As noted earlier, the problems of population aging are much more serious in rural areas than in urban areas because of the continuing massive rural-urban migration of young people. A closely related problem is that the ratio of male to female babies born in rural areas is much higher than in urban areas. This trend is bolstered by social and cultural traditions and by the reality that the elderly in rural areas rely on their sons for financial support, given that the old-age insurance program there is still weak. The old Chinese saying, "having a son for old-age support (养儿防老)," explains why rural residents who have no pensions strongly want to have at least one son. This, in turn, is the basic cause of the high male-tofemale ratio of births in the PRC.

We propose that the government work to make the old-age insurance program, set up nationwide in 2009-2010, stronger in rural areas. This program is developing quickly, but it is still much weaker in rural than in urban areas. Under a strengthened program, there would be compulsory participation in the old-age insurance program in rural areas, and the premiums would be jointly paid by individuals and the local and central governments. The state should ensure a basic income level for all rural elderly who participate in the program. Currently, the basic income level ensured by the state after retirement in rural areas is substantially lower than in urban areas. This is clearly unfair, and should be corrected as soon as possible as part of a policy of giving rural and urban residents equal benefits.

The further strengthening of the old-age insurance program in rural areas could largely reduce the necessity for rural residents to have at least one son for the sake of old-age care. Consequently, sexselective abortions motived by the preference for male babies would be reversed, along with the dangerous trend of higher male-to-female sex ratios at birth in the rural areas. 


\section{Gradually Raise the Retirement Age}

If the average retirement age in the PRC were gradually raised from its current very low level to the international standard (age 65 for men and women) by 2050, a rather conservative assumption, the annual pension deficit would be largely reduced or even eliminated under various demographic scenarios. A reconsideration of the PRC's low retirement age would be a good step toward addressing the challenges of population aging. A gradual increase in the retirement age, in addition to the universal two-child policy, implemented in 2016, will help the country avoid the problem of a rising pension deficit.

Continuing to work, rather than retiring, would also help the elderly who are able to work to continue having active and healthy lives, thereby increasing elderly vitality. Society would also benefit from the experience and skills of older adults. Some policy makers and scholars in the PRC argue that delaying the age of retirement might reduce job opportunities for young people entering the workforce. For this reason, they oppose raising the compulsory retirement age. This argument is incorrect, however. The problem of inadequate job opportunities for the young can be resolved or reduced by developing more labor-intensive and job-creating businesses, especially in the service sector, and by supporting longer education and professional training periods for the young.

Another policy option would be to allow the young and old to work fewer hours a week, but to extend the years of work before retirement (Vaupel 2010). This policy could play a critical role in resolving the perceived conflict between the goal of encouraging more healthy elderly to stay employed in order to reduce pension deficits and the goal of creating more job opportunities for the young. It could also contribute to improvements in the health and vitality of the elderly who are working. A shorter workweek would reduce the stress of heavy workloads and give people more free time, which could stimulate tourism and other leisure and social activities, thereby creating more jobs. It might also encourage young people to have more children.

\section{CONCLUSIONS}

This paper argues that it is important to develop public and private programs to provide individualized healthy aging services in order to meet the various needs of the PRC's growing elderly population. These programs should include long-term and acute daily care for the disabled; employment opportunities for the active elderly; programs for social and leisure activities, learning, and tourism; and programs for remarriage or partnership bridging. Among the policies that could be implemented to promote healthy aging, the priority should be on strengthening services and intervention programs to improve the psychological well-being of the elderly.

The PRC's very low compulsory retirement age should be gradually raised because it is restricting work life spans and the vitality of the elderly. Strengthening the quickly developing rural old-age insurance program would not only reduce the serious problems associated with aging in rural areas, it would also create a huge amount of capital through the collection of premiums from hundreds of millions of young and middle-aged participants; these premium payments could then be useful for economic development. 


\section{REFERENCES}

Banister, J., D.E. Bloom, and L. Rosenberg. 2010. Population Aging and Economic Growth in China. Harvard University Program on the Global Demography of Aging Working Paper Series. No. 53. Cambridge, MA: Harvard University.

Blazer, D.G., G. Fillenbaum, and B. Burchett. 2001. The APOE-E4 Allele and the Risk of Functional Decline in a Community Sample of African American and White Older Adults. The Journals of Gerontology: Series A. 56 (12). pp. M785-M789.

Chan, K.Y., W. Wang, J J. Wu, L. Liu, E. Theodoratou, J. Car, L., et al. 2013. Epidemiology of Alzheimer's Disease and Other Forms of Dementia in China, 1990-2010: A Systematic Review and Analysis. Lancet. 381 (9882). pp. 2016-2023.

Christensen, K., M. Thinggaard, A. Oksuzyan, T. Steenstrup, K. Andersen-Ranberg, B. Jeune, M. McGee, and J.W. Vaupel. 2013. Physical and Cognitive Functioning of People Older than 90 Years: A Comparison of Two Danish Cohorts Born 10 Years Apart. Lancet. 382 (9903). pp. 1507-1513.

Coale, A.J., and S.M. Li. 1991. The Effect of Age Misreporting in China on the Calculation of Mortality Rates at Very High Ages. Demography. 28 (2). pp. 293-301.

Field, D., and R.E. Millsap. 1991. Personality in Advanced Old Age: Continuity or Change? Journal of Gerontology. 46 (6). pp. P299-P308.

Gu, D., and M.E. Dupre. 2008. Assessment of Reliability of Mortality and Morbidity in the 1998-2002 CLHLS Waves. In Y. Zeng, D.L. Poston, D.A. Vlosky, and D. Gu, eds. Healthy Longevity in China: Demographic Methods and Population Analysis. Vol. 20. Dordrecht, The Netherlands: Springer.

Kahn, J. H., R. M. Hessling, and D. W. Russell. 2003. Social Support, Health, and Well-Being among the Elderly: What Is the Role of Negative Affectivity? Personality and Individual Differences. 35 (1). pp. 5-17.

Liang, Y., A. Song, S. Du, J. M. Guralnik, and C. Qiu. 2015. Trends in Disability in Activities of Daily Living among Chinese Older Adults, 1997-2006: The China Health and Nutrition Survey. Journals of Gerontology: Series A. 70 (6): 739-745.

Peng, X. 2011. China's Demographic History and Future Challenges. Science. 333 (6042). pp. 581-587.

Poston, D. L., Jr., and H. Luo. 2004. Age Structure and Composition of the Chinese Minorities in 2000 (In Chinese). Chinese Minority Populations. 19 (3). pp. 9-15.

Prince, M., V. Patel, S. Saxena, M. Maj, J. Maselko, M.R. Phillips, and A. Rahman. 2007. No Health without Mental Health. Lancet. 370 (9590). pp. 859-877.

Thatcher, A.R., V. Kannisto, and J.W. Vaupel. 1998. The Force of Mortality at Ages 80 to 120. Vol. 5. Odense Monographs on Population Aging. Odense, Denmark: Odense University Press.

Vaupel, J.W. 2010. Biodemography of Human Ageing. Nature. 464. pp. 536-542. 
Wang, Z., Y. Zeng, B. Jeune, and J.W. Vaupel. 1998. Age Validation of Han Chinese Centenarians. Genus. $54(1-2)$. pp. 123-141.

Wu, Y. T., H. Lee, S. Norton, A.M. Prina, J. Fleming, F.E. Matthews, and C. Brayne. 2014. International Journal of Geriatric Psychiatry. 29 (12). pp. 1212-1220.

Xiong, W., D. Gu, and Y. Zeng. 2019. Single-Age-Specific Life Tables (Ages 0-105) by Sex and Urban/ Rural Areas Based on the Sixth National Population Census of China. Unpublished.

Zeng, Y. 2011. Effects of Demographic and Retirement-Age Policies on Future Pension Deficits, with an Application to China. Population and Development Review. 37 (3). pp. 553-569.

Zeng, Yi. 2012. Towards Deeper Research and Better Policy for Healthy Aging-Using the Unique Data of Chinese Longitudinal Healthy Longevity Survey. China Economic Journal. 5 (2-3). pp. 131-149.

Zeng et al. 2016. Demographics, Phenotypic Health Characteristics and Genetic Analysis of Centenarians in China. Mechanism of Aging and Development. 165 (Pt. B). pp. 86-97.

Zeng, Y., Q. Feng, T. Hesketh, K. Christensen, and J.W. Vaupel. 2017. Survival, Disabilities in Activities of Daily Living, and Physical and Cognitive Functioning among the Oldest-Old in China: A Cohort Study. Lancet. 389 (10079). pp. 1619-1629.

Zeng, Y., and D. Gu. 2008. Reliability of Age Reporting among the Chinese Oldest-Old in the CLHLS Datasets. In Y. Zeng, D.L. Poston, Jr., D.A. Vlosky, and D. Gu, eds. Healthy Longevity in China: Demographic, Socioeconomic, and Psychological Dimensions. Dordrecht, Netherlands: Springer.

Zeng, Y., and J.W. Vaupel. 2002. Functional Capacity and Self-Evaluation of Health and Life of the Oldest Old in China. Journal of Social Issues. 58 (4). pp. 733-748.

Zeng, Y., and Z. Wang. 2014. A Policy Analysis on Challenges and Opportunities of Population/Household Aging in China. Journal of Population Ageing. 7 (4). pp. 255-281.

Zeng, Y., K.C. Land, D. Gu, and Z. Wang. 2014. Household and Living Arrangement Projections: The Extended Cohort-Component Method and Applications to the U.S. and China. Dordrecht, Netherlands: Springer. 


\section{Promoting Old-Age Vitality in the People's Republic of China}

In the People's Republic of China (PRC), the aging of the population is a far more serious problem in rural areas than in cities. This paper examines old-age vitality in the PRC, and its associated factors (such as physical and mental health), using the Chinese Longitudinal Healthy Longevity Survey and census data sets. The paper also recommends policies to better meet the needs of the PRC's elderly population, especially in rural areas. These include strengthening services to improve the mental health of the elderly, further developing the rural old-age insurance program, and gradually raising the retirement age.

\section{About the Asian Development Bank}

ADB is committed to achieving a prosperous, inclusive, resilient, and sustainable Asia and the Pacific, while sustaining its efforts to eradicate extreme poverty. Established in 1966, it is owned by 68 members49 from the region. Its main instruments for helping its developing member countries are policy dialogue, loans, equity investments, guarantees, grants, and technical assistance. 